\title{
BRASÍLIA: A SÃO PETERSBURGO BRASILEIRA?
}

\section{BRASILIA: BRAZILIAN SAINT PETERSBURG?}

\author{
EKATERINA VÓLKOVA AMÉRICO* \\ EDELCIO AMÉRICO**
}

RESUMO: A partir do conceito de "texto da cidade", formulado nos trabalhos de Iúri Lotman e Vladimir Toporov, no âmbito dos estudos empreendidos pela Escola Semiótica de Tártu-Moscou nos anos 1970-1980, o artigo aborda a presença, na cultura russa, de São Petersburgo como uma capital criada artificialmente por um capricho do Imperador Pedro, o Grande no século XVIII, e a possibilidade de traçar algumas semelhanças com a cidade de Brasília na cultura brasileira, como, por exemplo, na crônica "Nos primeiros começos de Brasília", de Clarice Lispector, que registrara as primeiras impressões da escritora sobre a capital recém-construída.

PALAVRAS-CHAVE: Texto da cidade. Semiótica. São Petersburgo. Brasília.

ABSTRACT: From the concept of "text of the city", formulated in the works of Yuri Lotman and Vladimir Toporov, within the

* Docente da UFF - Universidade Federal Fluminense. E-mail: katia-v@ya.ru .

** Docente da UFRJ - Universidade Federal do Rio de Janeiro.

E-mail: edelcioamerico@yahoo.com.br. 
studies undertaken by Tartu-Moscow Semiotic School in the decades of 1970-1980, the article deals with the presence in the Russian culture of Saint Petersburg as a capital created artificially by a whim of the Emperor Peter, the Great in the eighteenth century, and the possibility to draw some similarities with the city of Brasilia in Brazilian culture, such is in Clarice Lispectors' chronic "Nos primeiros começos de Brasília (In the early beginnings of Brasilia)", that recorded the writer's first impressions of the newly built capital.

KEYWORDS: Text of the City. Semiotics. Saint Petersburg. Brasilia.

\section{Introdução}

Na história de todos os países há cidades cujo impacto cultural é especialmente notável. A representação dessas cidades em diversas obras folclóricas e literárias revela certos motivos recorrentes, o que permite definir um único "texto da cidade". Assim, é possível falar de textos de São Petersburgo e Moscou na cultura russa (AMÉRICO, 2006; AMÉRICO, 2011), de texto de Roma, Veneza, Praga e assim por diante.

0 termo "texto da cidade" nasceu no âmbito da Escola Semiótica de Tártu-Moscou (1960-1980) e foi abordado nos trabalhos dos seus criadores: Vladímir Toporov (2003) e Iúri Lotman (2002). Embora na obra desses autores o conceito tenha sido aplicado em especial à cidade de São Petersburgo, fundada em 1703, pelo Imperador Pedro, o Grande, com o objetivo de criar uma capital europeia em solo russo, acreditamos que ele possa ser de grande utilidade para o estudo do papel cultural de outras cidades como, por exemplo, da pre- 
sença de Brasília na cultura brasileira.

Como uma das características formadoras do texto da cidade, Iúri Lotman destaca a capacidade das cidades de criar e acumular códigos e sinais a serem decifrados:

A cidade, como um mecanismo semiótico complexo, gerador da cultura, pode realizar essa função apenas porque representa em si um caldeirão de textos e códigos multiformes e heterogêneos, que pertencem a línguas e níveis diferentes. Justamente o poliglotismo semiótico essencial de qualquer cidade a torna um campo diversificado em que ocorrem colisões semióticas, impossíveis em outras condições. Ao somar diversos códigos e textos nacionais, sociais e estilísticos, a cidade realiza todo tipo de hibridações, codificações e traduções semióticas que a transformam em um poderoso gerador de uma nova informação (LOTMAN, 2002, p. 209, tradução nossa).

Assim, a cidade pode ser vista como um texto para ser lido e interpretado. A capacidade de uma cidade de se expressar por meio da sua própria linguagem foi observada também pelo escritor uruguaio Angel Rama:

As cidades desenvolvem suntuosamente uma linguagem mediante duas redes diferentes e superpostas: a física, que o visitante comum percorre até perder-se na sua multiplicidade e fragmentação, e a simbólica, que a ordena e interpreta, ainda que somente para aqueles espíritos afins, capazes de ler como significações o que não são nada mais que significantes sensíveis para os demais, e, graças a essa leitura, reconstruir a ordem (RAMA, 1985, p. 53).

O texto da cidade é refletido na cultura popular e de massas; de lá ele é extraído pela consciência individual do escritor para ser interpretado em suas obras literárias. Nas páginas a 
seguir, pretendemos destacar alguns dos traços recorrentes que permitem definir o "texto de São Petersburgo", bem como traçar algumas semelhanças com a cidade de Brasília.

\section{A fundação}

O nascimento de uma cidade sempre é acompanhado do mito que decorre de sua fundação. De acordo com o mitólogo russo-soviético Eleazar Meletínski, esse mito reproduz uma das narrativas mais arquetípicas da humanidade: a vitória do Cosmos sobre o Caos:

Não se deve esquecer que, na mitologia, a própria descrição de mito é possível somente em forma de narrativa da formação dos elementos desse mundo, e mesmo do mundo com um todo. Isso se explica pelo fato de que a mentalidade mítica identifica o começo (a origem) e a essência, por isso mesmo dinamizando e narrativizando o modelo estático do mundo. Sendo assim, o pathos do mito começa bastante cedo a reduzir-se à cosmicização do caos primordial, à luta, e à vitória do cosmos sobre o caos (isto é, a formação do mundo redunda, ao mesmo tempo, em seu ordenamento). Justamente esse processo de criação do mundo é o principal objeto da representação e o principal tema dos mitos mais antigos (MELETÍNSKI, 1998, p. 38-39).

Em linhas gerais, o esquema do mito de formação pode ser apresentado da seguinte forma:

INÍCIO (Caos) $\square$ CRIAÇÃo (Demiurgo) $\square$ FIM (Destruição) 
Nesse processo, o fundador da cidade também é mitologizado: são atribuídos a ele traços de um demiurgo. No que diz respeito a São Petersburgo, a figura de demiurgo é representada pelo seu criador: Pedro, o Grande, que, no início do século XVIII, ergueu, às margens do Mar Báltico, a nova capital da Rússia. Se a história de São Petersburgo se estende por mais de 300 anos, a narrativa mitológica de Brasília é muito mais recente, mas mesmo assim é possível observar a atribuição de traços demiúrgicos aos criadores da capital brasileira: Juscelino Kubitschek, Lúcio Costa e Oscar Niemeyer.

Por outro lado, todo mito de criação implica, necessariamente, outro mito: o escatológico, sobre a destruição e a volta do caos. 0 mito escatológico é muito presente nas narrativas sobre São Petersburgo e a história parece ter colaborado para a sua consolidação, pois desde a sua fundação a cidade sofreu inúmeras inundações:

Essa cidade, criada contra a vontade da natureza, encontra-se em conflito com a mesma, o que permite uma possibilidade dupla de sua interpretação: como vitória do intelecto sobre os elementos naturais, por um lado, e como perversão da ordem natural, por outro (LOTMAN, 2002, p. 209, tradução nossa).

Dessa forma, o mito escatológico se fundamenta em outra narrativa arquetípica: a quebra da ordem natural, a criação de uma cidade artificial no lugar antes tomado pela natureza, o que implica, necessariamente, na ideia do restabelecimento futuro da ordem original.

O filósofo romeno-francês Mircea Eliade atentou para outro aspecto importante: uma das relações essenciais entre o homem antigo e o seu habitat era a sacralização do espaço circundante. Um dos primeiros passos de sacralização do es- 
paço é o estabelecimento do seu Centro, do seu eixo central. 0 homem esperava por um sinal divino para reconhecer o local no qual a cidade deveria ser construída. Em decorrência disso, em diversas lendas sobre a fundação das cidades, há o motivo da "indicação divina". Geralmente, essa indicação ocorre mediante interferência de forças da natureza, às vezes representadas por animais:

Um exemplo: persegue-se um animal feroz e, no lugar onde o matam, eleva-se o santuário; ou então se põe em liberdade um animal doméstico - um touro, por exemplo -, procuram-no alguns dias depois e sacrificam-no ali mesmo onde o encontraram. Em seguida levanta-se um altar e ao redor dele constrói-se a aldeia. Em todos esses casos, são os animais que revelam a sacralidade do lugar, o que significa que os homens não são livres para escolher o terreno sagrado, e que os homens não fazem mais do que procurá-lo e descobri-lo com a ajuda de sinais misteriosos (ELIADE, 1992, p. 20).

As lendas sobre a fundação de São Petersburgo narram que, no momento do assentamento da primeira pedra da nova cidade, por Pedro, pairava uma águia sobre o local. 0 fato de ser uma águia é simbólico, pois o pássaro, presente no brasão da Rússia, simboliza o país como um todo. Dessa forma, no caso do mito de fundação de São Petersburgo, observa-se uma combinação de traços mitológicos antigos e recentes, de caráter político. No caso da fundação de Brasília, encontramos os resquícios desse mito na própria forma da cidade, projetada por Lúcio Costa como uma enorme borboleta, parecida também com uma cruz. A forma da cruz, aliás, está diretamente relacionada à sacralização do espaço: assim, na história da colonização da América Latina "a ereção da Cruz equivalia à consagração da região e, portanto, de certo modo, a um 'novo nascimento'“ (ELIADE, 1992, p. 22). Além disso, o famoso so- 
nho de Dom Bosco sobre a Terra Prometida (ALMINO, 2007), contribui também para a ideia da fundação de Brasília, predestinada pela vontade divina e não humana.

Ambas as cidades, São Petersburgo e Brasília, nasceram com o objetivo de ser uma nova capital. São Petersburgo foi criada para substituir Moscou, que simbolizava, para Pedro, uma Rússia atrasada e retrógrada que ele ansiava por transformar; no caso de Brasília, a capital foi transferida do Rio para Brasília, que objetivava representar a ordem e o progresso. Porém, aqui há uma diferença substancial: se a nova capital russa foi transferida do centro para periferia, no Brasil o movimento foi contrário: da periferia (das cidades litorâneas, como Salvador e Rio de Janeiro) para o centro do país.

Segundo Eliade (1992, p. 22), a fundação de uma cidade assemelha-se ao processo de sacralização do espaço: ocorre a apropriação do território, antes considerado "alheio", transformado em "nosso". A partir disso, pode-se supor que o objetivo de Pedro, o Grande, era "sacralizar" os espaços limítrofes do Império Russo às margens do Mar Báltico; já a interiorização da capital brasileira visava apropriar-se dos territórios internos, porém, pouco explorados.

Para uma consciência religiosa, depois de instalar-se em um novo território, é necessário consagrá-lo. Os povos antigos fixavam, na terra conquistada, um pilar sagrado que simbolizava o centro do universo, uma espécie de "umbigo do mundo", que ligava esse local ao universo dos deuses (ELIADE, 1992, p. 24). Quando foram conquistadas as terras onde se planejava erguer São Petersburgo, o Imperador Pedro ordenou a construção da Fortaleza de Pedro e Paulo. Por um lado, ela se mostrava como uma edificação militar cujo objetivo era proteger as terras de possíveis pretensões dos antigos "proprietários", os suecos; por outro, era uma forma de sacra- 
lização do espaço recém-conquistado. No Plano Piloto brasiliense, a função desse "centro sacral" é desempenhada pelo Palácio da Alvorada e pela Esplanada dos Ministérios.

\section{As oposições}

Se Eliade relaciona a formação da cidade com a sacralização do espaço, Angel Rama desenvolve a oposição ordem/ desordem:

A ordem deve ser estabelecida antes mesmo de que a cidade exista, para impedir assim toda futura desordem. [...] Uma cidade, previamente a sua aparição na realidade, devia existir em uma representação simbólica que obviamente só podia assegurar os signos: as palavras que traduziam a vontade de edificá-la na aplicação de normas e, subsidiariamente, nos diagramas gráficos que as desenhavam nos planos, [...] na imagem mental que desses planos tinham os fundadores. [...] Pensar a cidade competia a esses instrumentos simbólicos que estavam adquirindo sua pronta autonomia, que os adequaria ainda melhor às funções que lhes reclamava o poder absoluto (RAMA, 1985, p. 29).

0 conceito de ordem é profundamente ligado à fundação de São Petersburgo, pois a capital nortenha russa não surgiu naturalmente, a partir de um pequeno povoado, mas foi projetada minuciosamente por Pedro, o Grande, com o objetivo de ser uma nova capital para um novo Império. A construção de São Petersburgo visava recusar o passado tradicional e atrasado e proclamar o futuro: a Rússia deveria tornar-se um grande império europeu. A ideia da ordem que vence o caos refletiu-se nas ruas e avenidas retas de São Petersburgo, todas paralelas e perpendiculares. 
No entanto, esse desejo humano de ordenar o espaço entra em conflito com o universo da natureza, para o qual não existem linhas retas nem perfeição geométrica. Assim, por exemplo, a via central da cidade, a Avenida Niévski, curiosamente começa e termina no rio Nevá. A aspiração humana de domar a natureza caótica marcou toda a história da cidade de São Pedro:

A polaridade dessa estrutura petersburguense está no fato de que a natureza, oposta à cultura, não somente entra nessa estrutura [...], mas se iguala a ela. Desse modo, Petersburgo, como uma cidade grande, não é um resultado da vitória e de um triunfo completo sobre a natureza, mas, sim, um lugar em que [...] ocorre uma regência dupla: da natureza e da cultura (TOPOROV, 2003, p. 35, tradução nossa).

Apesar das ruas planejadas, que visavam possibilitar a São Petersburgo uma perfeita visibilidade, a cidade quase sempre está encoberta por uma neblina, resultado da construção sobre uma região pantanosa. De acordo com Toporov, essa característica torna a cidade transparente e fantasmagórica ao mesmo tempo:

Dessa correlação [...] entre natureza e cultura surgem situações típicas petersburguenses; por um lado, há um caos escuro e fantasmagórico no qual nada se vê com clareza [...], o existente e o não existente trocam de lugar, um finge ser o outro, misturando-se, juntando-se e provocando o observador (miragem, sonho, fantasma, sombra, sósia, reflexos nos espelhos, "diabruras petersburguenses"); por outro lado, existe um cosmos claro e transparente: uma união ideal entre a natureza e a cultura, caracterizada por lógica, harmonia, muita clareza e até clarividência (TOPOROV, 2003, p. 41). 
A capital brasileira também representa a ideia de ordem. Assim como São Petersburgo, Brasília é uma cidade criada e planejada artificialmente de acordo com o Plano Piloto. Entretanto, se Petersburgo teve como seu modelo, ou melhor, modelos, várias cidades europeias, representando uma "cidade-citação", Brasília foi concebida como uma cidade totalmente nova, cujas construções principais visavam não copiar, mas inovar, encarnando a ideia de progresso. Em outras palavras, se a fundação de São Petersburgo baseava-se na ideia de copiar o modelo europeu, a criação de Brasília simbolizava uma busca por algo essencialmente autêntico e brasileiro. Esse fato refletiu-se até mesmo no nome da nova capital. Quando Pedro criou São Petersburgo no limite do seu Império, o seu objetivo era "abrir" o país, então conservador, para o mundo exterior. Já no caso de Brasília, temos o movimento oposto: a posição litorânea e extrema da antiga capital, Rio de Janeiro, foi negada. A nova capital foi transferida para o centro do país, o que corrobora ainda mais com a ideia da fundação de uma cidade autenticamente brasileira.

Lotman divide as cidades em concêntricas e excêntricas (limítrofes). A cidade do primeiro tipo: "se apresenta como intermediária entre o céu e a terra, ao redor dela se concentram os mitos do plano genético (na formação dela, comumente, há a participação de Deus); ela tem início, mas não possui o fim, é uma 'cidade eterna'" (LOTMAN, 2002, p. 208).

Já a cidade excêntrica é a que se localiza "no limite" do espaço cultural: à beira mar, à margem do rio. Nesse caso, não temos a antítese "céu/terra", mas a oposição "natural/artificial". Ao estender essa classificação para São Petersburgo e Brasília, podemos reconhecer a primeira como excêntrica e a segunda como concêntrica. A ligação dessa última com o céu, inclusive, estava prevista no próprio Plano Piloto: 
Da proposta de plano-piloto resultou a incorporação à cidade do imenso céu do planalto, como parte integrante e onipresente da própria concepção urbana: os "vazios" são preenchidos pelo céu e a cidade é deliberadamente aberta aos $360^{\circ}$ do horizonte que a circunda (GUTEMBERG et al., 2002, p. 85).

Entretanto, a capital brasileira, ao mesmo tempo, é dotada de traços de uma cidade excêntrica, posicionada à beira de um território desconhecido e pouco explorado.

Ambas as capitais foram edificadas em um prazo miraculoso. São Petersburgo levou dez anos (desde a fundação em 1703 até a inauguração em 1712) para ser concluída, o que foi possível mediante sacrifício de milhares de vidas dos camponeses que trabalharam durante a construção. Devido a isso, Petersburgo ficou conhecida como a cidade "construída sobre ossos". A parte central de Brasília foi erguida em quase quatro anos, mas também há relatos de mortes, de operários enterrados no concreto e no controverso Massacre da Pacheco Fernandes. A partir dessas narrativas, surge uma imagem dúbia de ambas as capitais: por um lado, positiva, divina, majestosa e ordenada e, por outro, negativa, antinatural e perversa. A transformação de ambas as cidades em capitais da burocracia igualmente contribui para isso.

A oposição entre a cidade e a natureza também está presente na mitologia de Brasília, fundada, assim como São Petersburgo, em um lugar visto, na cultura popular, como inóspito e domado pela natureza. Se no caso de São Petersburgo o clima inóspito provinha dos pântanos, da umidade e do frio, em Brasília era o cerrado e a seca, como pode ser visto nos versos de Vinícius de Moraes (GUTEMBERG et al., 2002, p. 183): 
No início era o ermo:

Eram antigas solidões sem mágoa.

0 altiplano, o infinito descampado.

No princípio era o agreste:

0 céu azul, a terra vermelho pungente

E o verde triste do cerrado.

No caso de São Petersburgo, a violação das leis da natureza e a fundação da cidade em um lugar de condições climáticas impróprias contribuíram para a criação do epíteto "fábrica de mortes":

O papel das condições climáticas na eliminação da vida das pessoas em Petersburgo era muito significativo [...]: muitos que vieram para a cidade não conseguiram se adaptar às condições climáticas naturais e morriam devido a resfriados, pneumonias, tísicas ou simplesmente devido a queimaduras causadas pelo frio, fato sobre o qual testemunha a imprensa de São Petersburgo (TOPOROV, 2003, p. 31).

Ao passo que em Brasília, encontramos algumas semelhanças em constantes relatos na imprensa sobre a quantidade crescente de doenças respiratórias provocadas pela seca e, mais recentemente, pela poluição, queimadas e desmatamento (GUTEMBERG et al., 2002, p. 47).

Além disso, a priorização da ordem no planejamento da cidade de Brasília resultou na desconsideração das simples necessidades humanas:

Há uma ausência deliberada de espaços públicos em que as pessoas possam se reunir e conversar, ou simplesmente olhar uma para outra e passar o tempo. A grande tradição do urbanismo latino, em que a vida urbana se organiza em torno de uma grande praça, é rejeitada de modo explícito (BERMAN, 2010, p.13). 
A partir dessas linhas, é possível destacar mais uma oposição presente em ambas as cidades: entre o homem e o estado, entre o individual e o coletivo.

Além disso, assim como a São Petersburgo europeia, Brasília, em que "a grande tradição do urbanismo latino... é rejeitada", também é um elemento estranho, estrangeiro dentro do seu próprio país.

\section{A cidade literária}

De acordo com Angel Rama, toda cidade existe em dois planos: como uma cidade real e uma cidade letrada:

Visualizamos duas entidades diferentes que, como signo linguístico, estão unidas arbitrária, forçosa e obrigatoriamente. Uma não pode existir sem a outra, mas sua natureza e funções são diferentes assim como são diferentes os componentes do signo. Enquanto a cidade letrada atua preferencialmente no campo das significações e inclusive as autonomiza em um sistema, a cidade real trabalha mais comodamente no campo dos significantes e inclusive os afasta dos encadeamentos lógico-gramaticais (RAMA, 1985, p. 52).

Dessa forma, a noção da cidade letrada, sugerida por Ramos, aproxima-se do conceito de texto da cidade. 0 que une São Petersburgo e Brasília enquanto cidades letradas? 0 que faz traçar semelhanças entre os seus textos? Obviamente, é a sua artificialidade. Dostoiévski chamava São Petersburgo de "cidade mais abstrata e meditativa de todo o globo terrestre" (DOSTOIÉVSKI, 2000, p. 18). 0 seu caráter abstrato a torna meditativa e proporciona o surgimento de novos mitos:

A cidade artificial ideal, criada como realização da utopia ra- 
cionalista, devia ser privada da história já que a racionalidade "do estado regular" significava a renúncia das estruturas formadas durante a história. [...] A cidade-utopia racional foi privada dessas reservas semióticas. [...] A ausência de história levou a um crescimento intenso da mitologia. 0 mito preencheu o vazio semiótico e a situação da cidade artificial se mostra exclusivamente rica em geração de mitos (LOTMAN, 2002, p. 212).

O escritor João Almino explorou essa capacidade da capital do Brasil de gerar mitos em sua obra, tanto literária quanto crítica. Eis como ele define a simbologia cultural de Brasília:

Algumas cidades mostram de si uma imagem recorrente, como um palimpsesto ou uma fotografia antiga que permanecesse impressa, ainda que amarelecendo com o tempo, e conservasse seus traços por trás de outras, mais vivas e atuais. No caso de Brasília é imagem forjada pelo mito e também pela história de uma ideia, que se conclui com a execução do seu projeto modernista. Para dizer de outra forma, aquela cidade sem história é rica em carga simbólica. E o que Brasília simboliza? A democracia. A racionalidade. A nação. A integração e o desenvolvimento. A aspiração de igualdade. 0 moderno. 0 futuro. E também, claro, o poder, a alienação, o encastelamento, a corrupção, o autoritarismo, o misticismo e a irracionalidade (ALMINO, 2007, p. 299-300).

A artificialidade de Brasília, bem como a necessidade de criar novos mitos e até mesmo o novo homem, é o ponto de partida na crônica "Nos primeiros começos de Brasília", de Clarice Lispector, uma das primeiras a registrar as suas impressões sobre a cidade recém-fundada:

Brasília é construída na linha do horizonte. - Brasília é arti- 
ficial. Tão artificial como devia ter sido o mundo quando foi criado. Quando o mundo foi criado, foi preciso criar um homem especialmente para aquele mundo. [...] Brasília ainda não tem o homem de Brasília [...] (LISPECTOR, 1984, p. 452).

Observamos, nas linhas acima, a relação céu-terra, destacada por Lotman como um traço típico de uma cidade concêntrica. $\mathrm{O}$ ato de criação de Brasília é comparado ao ato de criação do mundo. Esse motivo também é destacado por Almino:

A maioria das cidades resulta do acaso, do encontro fortuito e da necessidade. Brasília é obra do espírito, da vontade e do plano. Se a experiência concreta daqueles que lá vivem ainda tem uma história curta, a história de Brasília como projeto, símbolo e mito se confunde com a do Brasil independente. É a história de uma utopia construída ao longo de um século e meio (ALMINO, 2007, p. 300).

Outro traço da cidade concêntrica é a sua santidade e eternidade. Na crônica de Clarice Lispector há ambos os motivos. Aliás, dessa relação surge também o paralelo entre os criadores da capital e os demiurgos:

0 ar religioso que senti desde o primeiro instante, e que neguei. Essa cidade foi conseguida pela prece. Dois homens beatificados pela solidão me criaram aqui de pé, inquieta, sozinha, a esse vento. [...] Eu sei o que os dois quiseram: a lentidão e o silêncio, que também é a ideia que faço da eternidade. Os dois criaram o retrato da cidade eterna (LISPECTOR, 1984, p. 455- 456).

Por outro lado, nela há também indícios de uma cidade excêntrica. Por exemplo, encontramos indicações de que a sua posição, não geográfica, mas imaginária, também seria limítrofe: “Em qualquer lugar onde se está de pé, criança pode cair, e 
para fora do mundo. Brasília fica à beira" (LISPECTOR, 1984, p. 453); "A cidade de Brasília fica fora da cidade" (p. 455). Ao que parece, aqui se trata dos limites com o mundo do além.

Ademais, há um típico motivo escatológico, decorrente do mito de criação: "A erosão vai desnudar Brasília até o osso" (LISPECTOR, 1984, p. 455). Não é ocasional o fato de que a destruição de Brasília, profetizada por Clarice, provém da natureza: como lembramos a partir das colocações de Lotman e Toporov, a ordem, violada pela construção da cidade, tem que ser restabelecida. Em outro trecho encontramos: "É urgente. Se não for povoada, ou melhor, superpovoada, uma outra coisa vá habitá-la. E se acontecer, será tarde demais: não haverá lugar para pessoas. Elas se sentirão tacitamente expulsas" (LISPECTOR, 1984, p. 454). O que seria essa "outra coisa"? A natureza, o cerrado domado? O Leviatã? Ou algo mais?

Quando Toporov e Lotman falam sobre Petersburgo na obra dos escritores russos, ambos destacam a influência que a cidade exerce sobre o ser humano, evidenciada pela citação abaixo:

Veja mais uma coisa: estou convencido de que muita gente em Petersburgo anda falando sozinha. Está é uma cidade de semiloucos. Se nós tivéssemos ciências ou médicos, juristas e filósofos poderiam fazer estudos valiosíssimos sobre Petersburgo, cada um na sua especialidade. É raro um lugar em que se encontrem tantas influências sombrias, grosseiras e estranhas sobre a alma humana como em Petersburgo. Só as influências climáticas, o que não significam! Por outro lado, é o centro administrativo de toda a Rússia, e o seu caráter deve refletir-se em tudo (DOSTOIÉVSKI, 2001, p. 476).

Há um tema parecido na crônica de Clarice Lispector, que relaciona certos estados de espírito ao fato de estar em Brasília: "Todo um lado de frieza humana que eu tenho, en- 
contro em mim aqui em Brasília, e floresce gélido, potente, força gelada da Natureza" (LISPECTOR, 1984, p. 454). Além da artificialidade, a natureza também predomina no texto brasiliense:

A artificialidade que invade a paisagem - a natureza reinventada pelos homens e que ainda guarda exemplos do gênio de Burle Marx - está também presente na flora do Plano Piloto. Falta de espaço é comum nas cidades modernas, onde os edifícios altos bloqueiam o horizonte. Ali é o contrário. Ante os amplos horizontes e a longa distância entre os prédios, os humanos se sentem pequenos e solitários (ALMINO, 2007, p. 306).

Brasília é tão artificial e futurista que chega a ser comparada à Lua: "Em Brasília estão as crateras da Lua" (LISPECTOR, 1984, p. 456). Ao que parece, essa comparação origina-se nas palavras do astronauta soviético Iúri Gagárin, ditas sobre a Brasília recém-construída logo após a sua viagem para o espaço: "Tenho impressão que estou desembarcando num planeta diferente, não na Terra" (GUTEMBERG et al., 2002, p. 11).

Uma das características de São Petersburgo é a amplitude do campo visual, a sua perfeita visibilidade, proporcionada pela geometria rigorosa das ruas e avenidas, que implica na extrema vulnerabilidade do transeunte:

Com o tempo, sobre todas as inclusões de classicismo renascentista, estilo imperial, gótico, e barroco, nos volumes de espaço de Petersburgo ergueu-se o princípio pan-ótico: visibilidade, uniformidade topológica e necessidade geométrica, ou seja, o princípio imperial de controle e do governo monárquico sobre todos os segmentos da realidade estatal a partir de qualquer um dos seus pontos (ISSÚPOV, 2000, p. 9, tradução nossa). 
No "texto de Brasília”, formulado por Clarice Lispector, há também esse motivo: tanto da sensação de vulnerabilidade quanto da cidade-estado que, através das suas janelas, vigia os atos dos seus súditos:

Esperei pela noite, como quem espera pelas sombras para poder se esgueirar. Quando a noite veio, percebi com horror que era inútil: onde eu estivesse, eu seria vista. 0 que me apavora é: vista por quem? - Foi construída sem lugar para ratos. Toda uma parte nossa, a pior, exatamente a que tem horror de ratos, essa parte não tem lugar em Brasília. Eles quiseram negar que a gente não presta (LISPECTOR, 1984, p. 453).

Essa sensação de ser vigiado pela cidade, pelo estado e até mesmo pelos céus eleva-se ao extremo quando surge a oposição entre a liberdade e a prisão: “Uma prisão ao ar livre. De qualquer modo, não haveria para onde fugir. Pois quem foge iria provavelmente para Brasília. Prenderam-me na liberdade!" (LISPECTOR, 1984, p. 454).

De modo geral, os textos de São Petersburgo e de Brasília se apresentam como estruturas semióticas semelhantes. No que diz respeito à proximidade entre a manifestação da cidade na obra de Fiódor Dostoiévski e de Clarice Lispector, deve ser levado em consideração o conhecimento profundo que a escritora brasileira de origem ucraniana tinha da obra de Dostoiévski e da literatura russa clássica em geral. Por exemplo, em $A$ hora da estrela a protagonista, Macabéa, ao ver o título Humilhados e ofendidos, pela primeira vez se dá conta de sua condição social (LISPECTOR, 1993, p. 56). Portanto, os paralelos apontados acima em parte podem ser explicados pela influência direta do autor russo.

Como observamos, é possível, sim, definir o texto de 
Brasília, o seu aspecto "letrado", como também é possível comparar esse texto com a imagem de São Petersburgo na cultura russa, porém com algumas ressalvas importantes. Em primeiro lugar, nota-se que o texto de Brasília é muito mais recente que o de São Petersburgo. Trata-se, portanto, de um texto ainda em formação, além do mais, ao contrário de Petersburgo, abordado em diversas obras da literatura russa, a quantidade de autores que situaram a sua obra em Brasília ainda é pequena.

A posição geográfica também é uma diferença essencial: assim, São Petersburgo é uma cidade limítrofe, já Brasília é localizada no centro. Se no texto de São Petersburgo predominam os motivos escatológicos, no texto de Brasília nota-se uma forte presença da ligação entre a terra e o céu, típica para uma cidade concêntrica.

Além disso, é preciso considerar na análise, que São Petersburgo em russo é um nome do gênero masculino, assim como a palavra cidade (górod), o que, em nossa opinião, resulta em sua manifestação mais ativa e até mesmo imperativa; já Brasília, assim como a palavra "cidade", por pertencer ao gênero feminino, revela uma influência mais sutil e materna nas personagens, além de ser associada à Natureza, mesmo que domada pelo homem.

Uma das marcas específicas do texto de São Petersburgo é a sua eterna comparação com a cidade de Moscou, essa sim famosa por suas características femininas (AMÉRICO, 2014). Em relação ao texto de Brasília, há também comparações com as antigas capitais, principalmente Rio de Janeiro, presentes, por exemplo, nas crônicas de Machado de Assis: apesar do seu engajamento na questão da transferência da capital, nota-se um leve tom de remorso saudoso pelo Rio de Janeiro que um dia deixaria de sê-la: 
A capital da República, uma vez estabelecida, receberá um nome deveras, em vez deste que ora temos, mero qualificativo. Não sei se viverei até à inauguração. [...] Mas, se viver, lá irei passar algumas férias, como os de lá virão aqui passar outras. Os cariocas ficarão sempre com a baía, a esquadra, os arsenais, os teatros, os bailes, a Rua do Ouvidor, os jornais, os bancos, a praça do comércio, as corridas de cavalos, tanto nos circos, como nos balcões de algumas casas cá embaixo, os monumentos, a companhia lírica, os velhos templos, os rebequistas, os pianistas... (ASSIS, 1893).

\section{Referências}

ALMINO, João. O mito de Brasília e a literatura. Estudos avançados, São Paulo, vol. 21, n. 59, p. 299-308, jan/abr, 2007.

AMÉRICO, Edelcio. Texto de São Petersburgo na literatura russa. Dissertação (Mestrado em Literatura e Cultura Russa) Faculdade de Filosofia, Letras e Ciências Humanas, São Paulo, 2006.

AMÉRICO, Edelcio. Os textos de Moscou e São Petersburgo como reflexo da identidade nacional russa. Tese (Doutorado em Literatura e Cultura Russa) Faculdade de Filosofia, Letras e Ciências Humanas, São Paulo, 2011.

AMÉRICO, Edelcio. A Imagem Feminina de Moscou na Literatura Russa. Rus - Revista de Literatura e Cultura Russa, n. 3, p. 18-29, 2014.

ASSIS, Machado de. A semana. [22 de janeiro de 1893]. 
Disponível em: <http://www.machadodeassis.ufsc.br/ obras/cronicas/CRONICA,\%20A\%20semana,\%201892. htm\#C1896>. Acesso em: 24 jan. 2016.

BERMAN, Marshall. Tudo que é sólido desmancha no ar. São Paulo: Editora Schwartz Ltda., 2010.

DOSTOIÉVSKI, Fiódor. Crime e castigo. [Tradução de Paulo Bezerra]. São Paulo: Editora 34, 2001.

DOSTOIÉVSKI, Fiódor. Memórias do subsolo. [Tradução de Boris Schnaiderman]. São Paulo: Editora 34, 2000.

ELIADE, Mircea. O sagrado e o profano. Martins Fontes, São Paulo, 1992. Disponível em: <http://gepai.yolasite.com/ resources/0\%20Sagrado\%20E\%200\%20Profano\%20-\%20 Mircea\%20Eliade.pdf>. Acesso em 20 jan. 2016.

GUTEMBERG, Cláudia et al. Brasília... em 300 questões. Brasília: Edições Dédalo, 2002.

ISSÚPOV, K. Diálogo das capitais no movimento histórico (Dialóg stolits v istorítcheskom dvijénii). In: Pro et Contra Moscou - Petersburgo (Pro et Contra Moskvá - Peterburg). Moscou: RGKHI, 2000.

LISPECTOR, Clarice. Nos primeiros começos de Brasília. In: A descoberta do mundo. Rio de Janeiro: Editora Nova Fronteira, 1984.

LISPECTOR, Clarice. A hora da estrela. Rio de Janeiro: Francisco Alves, 1993. 
LOTMAN, Iúri. Simbologia de São Petersburgo e os problemas da semiótica da cidade (Simvólika Peterburga i probliémy semiótiki góroda). In: História e tipologia da cultura russa (Istoria i tipológuia rússkoi kultury). São Petersburgo: Iskusstvo, 2002. p. 208-221.

MELETÍNSKI, Eleazar. Os arquétipos literários. São Paulo: Ateliê Editorial, 1998.

RAMA, Angel. A cidade das letras. São Paulo: Editora Brasiliense, 1985.

TOPOROV, Vladimir. 0 texto de São Petersburgo na literatura russa (Peterbúrgskii tekst rússkoi literatury). São Petersburgo: Iskusstvo, 2003.

Artigo recebido em março de 2016 e aprovado em julho de 2016.

\section{Como citar este trabalho:}

VÓLKOVA AMÉRICO, Ekaterina; AMÉRICO, Edelcio. Brasília: a São Petersburgo brasileira? CASA: Cadernos de Semiótica Aplicada, São Paulo, v. 14, n. 01, p. 129-150, julho, 2016. Disponível em: <http://seer.fclar.unesp.br/casa>. Acesso em "dia/mês/ano". http://dx.doi.org/10.21709/casa. v14i1.8435. 